\title{
Concepçóes de terapeutas ocupacionais acerca da linha do cuidado em saúde mental ${ }^{1}$
}

\author{
Michelle Helena Pereira de Paiva ${ }^{a}$, Heloísa Cristina Figueiredo Frizzo ${ }^{b, c, d}$ \\ aTerapeuta Ocupacional, Residência Integrada Multiprofissional em Saúde, \\ Universidade Federal do Triângulo Mineiro - UFTM, Uberaba, MG, Brasil \\ 'Docente no Curso de Graduação em Terapia Ocupacional, \\ Universidade Federal do Triângulo Mineiro - UFTM, Uberaba, MG, Brasil \\ ${ }^{c}$ Mestre em Saúde Mental, Faculdade de Medicina de Ribeirão Preto, \\ Universidade de São Paulo - USP, Ribeirão Preto, SP, Brasil \\ ${ }^{d}$ Doutoranda em Enfermagem, Programa Interunidades EERP/EE, \\ Universidade de São Paulo - USP, São Paulo, SP, Brasil
}

\begin{abstract}
Resumo: A linha do cuidado preconizada pelo Sistema Único de Saúde (SUS) deve ser realizada por todo profissional da área, pelo meio social e pelo sujeito. Este estudo visou conhecer as concepções dos terapeutas ocupacionais acerca da linha do cuidado em saúde mental. Os dados desta pesquisa foram obtidos a partir de um questionário encaminhado via rede virtual de contatos e técnica bola de neve. Os dados foram submetidos à análise quali-quantitativa. Os participantes são em sua maioria formados na região sudeste, com mais de cinco anos de formados. Atuam especialmente em hospitais psiquiátricos, Centros de Atenção Psicossocial (CAPS II) e Ambulatórios de Saúde Mental. Não houve registro de atuação em Serviços Residenciais Terapêuticos (SRT) e em Unidade de Atenção Básica à Saúde (UBS). Em relação à concepção da linha do cuidado, seis participantes não responderam e cinco desconhecem a expressão, seguida da concepção relacionada aos princípios da reabilitação psicossocial e do projeto terapêutico - apenas uma resposta identificou que se trata de uma prática baseada na gestão do cuidado com princípios de acolhimento e articulação de redes sociais e serviços. Os resultados evidenciaram que as práticas dos profissionais são pouco pautadas na lógica da linha do cuidado, no entanto destaca-se a necessidade de sistematização da atenção segundo esta para efetuação da Reforma Psiquiátrica, na busca da melhoria da qualidade de vida e resgate da cidadania das pessoas em sofrimento psíquico, na medida em que além de otimizar a rede de atenção também promove o cuidado integral e humanizado e a contratualidade social.
\end{abstract}

Palavras-chave: Saúde Mental, Terapia Ocupacional, Políticas Públicas de Saúde, Assistência em Saúde Mental.

\section{Occupational therapists' conceptions on mental health care line}

\begin{abstract}
The care line recommended by the Brazilian Health System - SUS must be attained by every professional of the area, milieu and subject. This study aimed to know the occupational therapists' conceptions about the line of care in mental health. The data of this study were obtained from a questionnaire sent via virtual network of contacts and snowball technique. Data were subjected to qualitative and quantitative analysis. Most participants were professionals from the southeast region of the country with over five years of training. They exercise the professional activity mainly in Psychiatric Hospitals, Psychosocial Assistance Centers - CAPS II and Mental Health Clinics. There was no registry of professional performance in Residential Therapeutic Services - SRT and Outpatient Clinics - UBS. Regarding care line, six participants did not respond and five were unaware of the term, followed by the psychosocial rehabilitation principles and therapeutic project; only one answer identified
\end{abstract}

Autor para correspondência: Michelle Helena Pereira de Paiva, Universidade Federal do Triângulo Mineiro, Av. Getúlio Guaritá, 159, Bairro Abadia, CEP 38025-440, Uberaba, MG, Brasil, e-mail: mhppaiva@gmail.com

Recebido em 17/6/2011; Revisão: 14/9/2011; Aceito em 22/3/2012. 
care line as a practice based on care management with reception principles and articulation of social networks and services. Results showed that the professionals' practices are little guided in care line logic; however, there is the need systematization of the assistance according this logic in order to apply the Psychiatric Reform, searching the quality of life improvement and reestablishment of the citizenship of people with psychological distress insofar as, in addition to optimizing the care network, which promotes comprehensive humane care and social contractualism.

Keywords: Mental Health, Occupational Therapy, Public Health Policies, Mental Health Assistance.

\section{Introdução}

A Reforma Psiquiátrica surgiu no Brasil nos anos 80, a partir da luta de trabalhadores, familiares e usuários de serviços de atenção à saúde mental na busca de uma prática menos estigmatizante e marcada por maus-tratos e a favor de uma prática pautada na reinserção social.

Foram propostas reformulaçóes nos serviços existentes e a criação de novos equipamentos de atenção (WACHHOLZ; MARIOTTI, 2009), constituindo-se na primeira década do século XXI o eixo das políticas públicas brasileiras de atenção à saúde mental, em busca da reinserção social da pessoa em sofrimento psíquico em seu contexto, considerando-a como sujeito de direitos sociais, em contraposição ao modelo hospitalocêntrico despersonificante e segregador e promovendo, assim, a desinstitucionalização e a inclusão.

Considerando-se a Reabilitação Psicossocial como eixo norteador de Reforma Psiquiátrica e que esta se configura como o processo que facilita ao usuário com limitaçôes a melhor reestruturação da sua autonomia e de suas funçóes na comunidade. Ela representa um conjunto de meios (programas e serviços) desenvolvidos para facilitar a vida de pessoas com problemas severos e persistentes em saúde mental, envolvendo programas de suporte comunitário como: trabalho, educação, esporte e lazer (PITTA, 1996).

Nesse sentido é um desafio para os profissionais de saúde sistematizarem suas práticas, pois trata-se da construção, ponto essencial da reabilitação psicossocial, que depende de variáveis que operam a favor da contratualidade em casa, no trabalho e na rede social, variáveis essas que estão na organizaçáo de pessoal dentro de um serviço, no tempo em que estão exercendo sua prática, em sua área de atuação, na hospitalidade que se oferece e na liberdade para tomar decisôes (SARACENO, 1996).
Em relação à atuação em Terapia Ocupacional, Mângia (2000) expóe que é necessário repensar a reabilitação a partir de vida cotidiana, em relação aos fatores que tornam as pessoas hábeis e inábeis e também como desempenham a contratualidade social; a terapia ocupacional tem deslocado os settings terapêuticos da profissão para os espaços do habitar, do trabalhar e do conviver, dessa forma os pacientes têm oportunidade de usar suas habilidades no mundo e o processo de reabilitação se transforma em um processo de reconstrução de redes sociais.

Esses desafios acima citados podem ser enfrentados a partir da articulação com pressupostos teóricos, envolvendo o raciocínio sobre a linha do cuidado em saúde mental, compreendendo-a como um conjunto de estratégias que têm por objetivo organizar o fluxo de indivíduos de acordo com suas necessidades. A rede de atenção deve organizar os recursos em diferentes níveis de atenção, para que seja garantido a todos o acesso aos serviços e ao cuidado integral.

A concepção da Linha do cuidado (LC) parte da missão institucional do estabelecimento/serviço de saúde, provendo mecanismos que garantam o cuidado (CECÍLIO, 1997). A LC é alimentada por recursos/insumos que expressam as tecnologias a serem consumidas pelos usuários durante o processo de assistência ao beneficiário, funcionando de forma sistêmica e operando vários serviços. Esta tem início na entrada do usuário em qualquer ponto do sistema que opere a assistência: seja no atendimento domiciliar, na equipe de saúde da família/atenção básica, em serviços de urgência, nos consultórios, em qualquer ponto onde haja interação entre o usuário e o profissional de saúde. O que é importante que se destaque é que a linha do cuidado acontece sempre em rede, uma noçáo que também deve ser sempre repensada em seus fluxos e hierarquizaçóes. Reconhecer e qualificar múltiplas portas de entrada na atenção à saúde é garantir acolhimento e atendimento aos segmentos populacionais mais vulneráveis que têm dificuldade de acesso aos serviços sociais e de saúde. Assim, a rede pode ser vista como de arranjo variável ou em círculo (CECÍLIO, 1997). 
Permite-se assim que se articule não apenas a rede de serviços em torno de uma necessidade de saúde, como que se articule a própria rede social de suporte. As linhas do cuidado, nesse sentido, são instrumentos interessantes não apenas para a gestão da produção do cuidado, mas para uma reorganização dos saberes e práticas do campo da produção da saúde (GALHEIGO, 2008).

A partir desse lugar de entrada, abre-se um percurso que se estende, conforme as necessidades do beneficiário, por serviços de apoio diagnóstico e terapêutico, especialidades, atenção hospitalar e outros (MALTA et al., 2004; CECÍLIO; MERHY, 2003). Segundo Cecílio e Merhy (2003), o desenho da LC entende a produção da saúde de forma sistêmica, a partir de redes macro e microinstitucionais, em processos extremamente dinâmicos, nos quais está associada à imagem de assistência ao beneficiário uma linha de produção, centrada em seu campo de necessidades.

A produção da saúde implica formatos institucionais que articulam respostas macro e microinstitucionais (CECÍLIO; MERHY, 2003), ou seja, para equacionar o caminhar na LC, ordena-se tanto o processo de trabalho em saúde quanto demandas de organizaçáo do sistema de saúde e suas interfaces.

Linhas de produção do cuidado, segundo Cecílio e Merhy (2003), são constituídas em funçẫo do usuário e de suas necessidades de saúde, considerando-se que essa produção do cuidado é constituída por processos de trabalho marcados pela micropolítica do trabalho vivo. Para esses autores, dispositivos organizacionais provocariam a necessidade permanente de diálogo, produção de compromisso e pactuação entre os cuidadores e gestores das diversas Unidades de Produção, a fim de garantir uma coordenação responsável e transversal das açóes de saúde, com o intuito de maximizar a integralidade, a integração, a resolutividade e a eficiência da atençáo. Os gestores das Linhas de Cuidado sáo responsáveis por coordenar a imbricada rede de cuidados e relaçóes necessárias ao alcance dos resultados enunciados acima, exigindo-se deles articulação permanente com Unidades de Produção do Cuidado.

Essa lógica, operada em diversos serviços de saúde, exigiu e resultou em mudanças: nos fluxos e critérios de encaminhamento internos entre uma unidade de produção e outra; no modelo de gestão de cada unidade que compóe uma determinada linha de cuidado e do conjunto da organização de serviços de saúde; na composição e organização das equipes; na organização do processo de trabalho; nas práticas de cuidado; na centralidade dada ao usuário.
Para Ceccim e Ferla (2006), o ordenamento da atenção e de uma rede de serviços em linha de cuidado implica, necessariamente, tanto para gestores, quanto para trabalhadores e usuários, o conhecimento dos fatores que beneficiam ou prejudicam, condicionam e/ou determinam os estados de saúde e os recursos existentes para sua prevenção, promoçáo e recuperação, assim como para o engendramento da afirmaçáo da vida, do cuidado de si e das conexóes em redes sociais.

A linha de cuidado implica:

[...] um redirecionamento permanente do processo de trabalho, onde o trabalho em equipe se constitui como de fundamental importância para a ampliação das compreensóes e interpretações, pois não é uma patologia ou um evento biológico o que flui por uma linha de cuidado, mas uma pessoa, um processo de subjetivação, uma existência encarnada num viver individual. Assim, ao longo do percurso, nuanças, sutilezas e transformaçóes podem e devem encontrar acolhida e projeto terapêutico, inclusive abrindo outros fluxos na grande malha de cuidados de uma rede de saúde [...] (CECCIM; FERLA, 2006 apud PINTO, 2009, p. 28).

Galheigo (2008) reflete sobre a possibilidade de a terapia ocupacional aproximar seus saberes e práticas da produção do cuidado em saúde assumindo a integralidade do cuidado e a construção de redes (redes de cuidado, redes sociais de suporte, redes de construção permanente de laços de cidadania) como eixo e marca de sua açáo.

Nesse sentido, a prática da terapia ocupacional no campo da saúde mental se aproxima dos pressupostos da clínica ampliada: a clínica centrada nos sujeitos, que considera a doença parte da existência e não a totalidade dela (CAMPOS, 2003). É aquela capaz de compreender o indivíduo e seus problemas de saúde, inseridos em um território e em redes sociais (família, espaços de trabalho e de convivência) e que se abre a perceber e ajudar o sujeito doente a construir sua percepçáo sobre a vida e o adoecimento (CUNHA, 2005).

Uma clínica que parte da concepção da coprodução singular dos sujeitos, das organizaçóes, dos processos saúde-doença e dos acontecimentos em geral (CAMPOS, 2006). Coproduçấo singular do sujeito pois, em espaços dialógicos, os indivíduos influenciam e são influenciados pelos sujeitos com quem interagem, em um dado momento, únicos. Sofrem interferências de fatores imanentes e transcendentes a eles próprios como, por exemplo, o contexto organizacional, 
cultural, político e sócio-econômico onde estáo inseridos e que, por sua vez, poderão ser determinantes de seus comportamentos.

Para Campos (2006), existe uma corresponsabilidade dos indivíduos e sujeitos coletivos sobre o processo saúde-doença e na construção dos contextos singulares. Embora múltiplos fatores se apresentem simultaneamente, o impacto de cada um deles sobre o status de saúde de um indivíduo ou da coletividade é diferente, dependendo do contexto. Governos, equipes de saúde, comunidade ou o próprio indivíduo podem ser isoladamente ou em conjunto, com iguais ou diferentes responsabilidades, os agentes fundamentais na produção de um determinado desfecho clínico ou sanitário.

Frente aos desafios aqui apresentados para a consolidação das políticas públicas brasileiras de atenção à saúde mental, na busca da Reforma Psiquiátrica, fazem-se necessários esforços dos diferentes saberes e práticas em saúde mental para que efetivamente a pessoa em sofrimento psíquico possa ser assistida em suas diferentes necessidades e em um dado contexto.

Sendo o terapeuta ocupacional profissional da área que tem como objetivo a inclusão social, a partir do resgate dos papéis sociais e do desempenho ocupacional, é fundamental que esses profissionais se apropriem dos pressupostos do raciocínio da linha do cuidado ao considerar que ela visa à afirmação da vida, do cuidado de si e das conexóes em redes sociais.

Este estudo objetivou conhecer as concepçóes de terapeutas ocupacionais acerca do raciocínio da linha do cuidado em saúde mental, acreditando que poderá contribuir para com o planejamento de açóes resolutivas para a pessoa em sofrimento psíquico ser acolhida, informada e direcionada a uma rede de serviços e cuidados inclusiva.

A realização da atenção em saúde mental realizada por terapeutas ocupacionais segundo os fundamentos da linha do cuidado pode contribuir para a efetivação da Reforma Psiquiátrica, para melhorar qualidade de vida e para manter a cidadania das pessoas portadoras de transtornos mentais na medida em que além de otimizar a rede de serviços também resgata a rede e a contratualidade social.

\section{Metodologia}

Trata-se de um estudo descritivo-exploratório, no qual os fatos são observados, registrados, analisados, classificados e interpretados sem que o pesquisador interfira neles. O estudo descritivo-exploratório busca informações precisas sobre a frequência de ocorrência de um fenômeno quando se sabe pouco sobre ele (LOBIONDO-WOOD; HABER, 2001), como no caso desta pesquisa, pois se sabe pouco sobre atuação profissional seguindo a linha do cuidado, uma vez que essa forma de organização das redes assistenciais ainda é recente.

Nesse estudo foi utilizada a abordagem qualitativa e quantitativa. Segundo Minayo e Gomes (2002), a pesquisa qualitativa trabalha com significados, motivos, crenças, valores e atitudes. A pesquisa também foi quantitativa, pois teve dados numéricos, além de propor uma análise quantitativa dos dados.

Ambas as metodologias podem ser combinadas, enquanto a metodologia quantitativa pretende descobrir a frequência e distribuição dos fatos, analisando os aspectos estruturais; a metodologia qualitativa objetiva conhecer a experiência subjetiva, analisando os aspectos processuais (FLICK, 2009).

Para a consecução desta pesquisa foi utilizado um questionário com questóes abertas e fechadas. Nele foram abordadas questôes sobre a atuação profissional em especial em saúde mental, considerando-se os objetivos, estratégias e abordagens utilizados nas intervençóes, as políticas públicas em saúde mental e suas respectivas bases teóricas e a prática baseada no raciocínio da Linha do Cuidado em Saúde Mental. A realização da coleta de dados se deu no período de janeiro a maio de 2010.

Definido por Gil (2006), o questionário é uma técnica de investigação composta por um número mais ou menos elevado de questôes apresentadas por escrito que objetivam conhecer as opiniôes, sentimentos e situaçôes vivenciadas pelos envolvidos. A vantagem de utilização do questionário é a possibilidade de atingir um grande número de pessoas, mesmo que estejam numa área geográfica extensa.

Os critérios de inclusão para participação do estudo foram: ser terapeuta ocupacional e atuar ou já ter atuado na área de saúde mental.

Participaram deste estudo terapeutas ocupacionais localizados através de Redes Virtuais em Terapia Ocupacional tais como: grupo de mensagens eletrônicas de participantes da Rede Nacional de Ensino e Pesquisa em Terapia Ocupacional (RENETO) e Terapia Ocupacional Libertária, além da utilizaçáo da técnica de bola de neve, que segundo Flick (2009) significa solicitar aos primeiros participantes endereços eletrônicos de outros possíveis participantes do estudo, especificamente, neste caso, terapeutas ocupacionais com atuação na área de saúde mental.

Inicialmente uma carta convite para a participaçáo neste estudo foi encaminhada a um acervo de 
aproximadamente 470 endereços eletrônicos, solicitando interesse para responder ao questionário, já enviado em arquivo anexo, nesta carta convite havia orientaçôes quanto ao preenchimento do questionário e do consentimento livre e esclarecido, que poderiam ser respondidos tanto on-line como por correio. Caso o participante optasse pelo correio convencional, ele deveria indicar dados para encaminhamento da documentação afim, para posterior postagem, inclusive envelope e selo para devolutiva do questionário de responsabilidade do pesquisador. $\mathrm{Na}$ carta convite também constavam possibilidades de indicação de endereços eletrônicos de outros terapeutas ocupacionais da área.

De acordo com Flick (2009), quando se utiliza o questionário on-line, as instruçôes devem ser claras e detalhadas, de modo que o sujeito de pesquisa saiba o que fazer/responder. Além disso, as instruçôes/ perguntas náo devem ser muito longas, a fim de evitar confusão/negligência do sujeito de pesquisa.

As variáveis quantitativas foram submetidas à análise estatística descritiva (frequência absoluta e relativa) e as variáveis qualitativas foram submetidas à análise de conteúdo temática, que é para Bardin (2004) como uma técnica de investigação por descrição objetiva, sistemática do conteúdo manifesto da comunicação, visando conhecer as variáveis de ordem psicológica, sociológica, histórica, dentre outras.

Este estudo foi aprovado pelo Comitê de Ética em Pesquisa da Universidade Federal do Triângulo Mineiro - UFTM, Uberaba, MG, através do parecer protocolado n. 1409/2009.

\section{Resultados e discussão}

Participaram do estudo 15 terapeutas ocupacionais com experiência na área de saúde mental, todas do sexo feminino, formadas em oito diferentes universidades. Dessas, seis universidades são particulares (PUC, Salesiano de Lins, CEUCLAR, Universidade Potiguar, Universidade do Vale do Paraíba e Uniube) e duas, públicas (UFSCar e UFMG). Cinco (33,33\%) participantes se formaram na Universidade Federal de São Carlos e três (20\%), na Pontifícia Católica de Campinas, ambas do estado de São Paulo.

O maior número de participantes, 14 (93,33\%) se formou na regiáo sudeste, sendo $11(73,33 \%)$ no estado de Sáo Paulo, número que, provavelmente, se deve ao fato de as primeiras universidades a oferecerem curso de terapia ocupacional serem da região sudeste.
Em relação ao tempo de formação, 9 (60\%) dos participantes tinham de dois a 10 anos de formação acadêmica, enquanto os demais - seis (40\%) - eram formados há mais de 10 anos. Esses dados permitem refletir que o primeiro grupo já estava em formação durante o período de consolidação das políticas públicas em saúde mental no Brasil no período de 2000 a 2010. Em contrapartida, o segundo grupo pode não ter recebido influência dos movimentos da luta pela Reforma Psiquiátrica no momento de sua formação.

Em relação à atuação dos profissionais nos serviços de atenção à saúde mental, os dados do gráfico 1 mostram a predominância de terapeutas ocupacionais em hospitais psiquiátricos $(\mathrm{N}=8 ; 26,67 \%)$ e em seguida em Centros de Atenção Psicossocial II (CAPS II) (N = 6; 20\%) e Ambulatório de Saúde Mental ( $\mathrm{N}=4 ; 13,34 \%)$. Não houve registros da atividade profissional de atenção à saúde mental junto a Unidades Básicas de Saúde e em Serviços Residenciais Terapêuticos.

Comparando-se esses dados da literatura especializada no assunto observa-se que há uma tendência de a atuação da profissão terapia ocupacional acompanhar a lógica e sistematização dos diferentes equipamentos/serviços em atenção à saúde mental.

Entre os anos de 2003 e 2006 houve redução significativa dos leitos psiquiátricos no Brasil. Segundo o Relatório de Gestão produzido pela Secretaria de Atenção à Saúde, em 2007 os estados da região sudeste ainda concentravam a maior parte dos leitos $(60,32 \%)$ e dos pacientes moradores, o que apontava para a necessidade de investimentos efetivos no processo de desinstitucionalização no restante do país (BRASIL, 2007).

Paralelamente, houve diminuição de recursos financeiros do Ministério da Saúde destinados aos hospitais psiquiátricos, ampliando-se os recursos para os serviços extra-hospitalares.

Observa-se que o número de leitos e de verba destinada aos hospitais psiquiátricos vêm diminuindo ao longo dos anos, porém ainda é maior do que a destinada aos outros serviços.

Atualmente, apesar da expansão da rede de atenção aberta e comunitária que permitiu a redução e a substituição significativa de leitos psiquiátricos e do fechamento de vários hospitais psiquiátricos em péssimas condições de funcionamento (BRASIL, 2007), ainda observa-se em muitas regiôes do país a centralidade da assistência em torno dos hospitais psiquiátricos. 
A partir desses dados é possível compreender a tendência de concentraçáo de intervenção terapêuticoocupacional nos hospitais psiquiátricos, uma vez que a centralização da assistência ainda se dá nesses locais.

Os principais objetivos de intervenção mencionados pelos participantes junto à atuação em um hospital psiquiátrico são: realizar oficinas, buscar reinserção social e socialização, favorecer poder contratual, promover o aprimoramento de habilidades e o potencial produtivo, romper com a separaçáo intra e extramuros, preparar para o retorno à comunidade; a partir das seguintes estratégias: atendimento em grupo e individual, promover atividades que favoreçam o contato social e a autonomia, realizar oficinas, festas extramuros e grupos de preparação para alta.

Podemos destacar como relevante a atuaçáo terapêutico-ocupacional junto aos CAPS, que se constituem como serviços de saúde que têm a função de prestar atendimento clínico em regime de atenção diária, evitando dessa forma internaçôes em hospitais psiquiátricos, além de promoverem a inserção social regular à rede de assistência em saúde mental e dar suporte à saúde mental na rede básica (BRASIL, 2005).

Os Centros de Atenção Psicossocial (CAPS) são serviços de saúde municipais, abertos e comunitários, devem ser substitutivos ao modelo hospitalocêntrico e não complementar (BRASIL, 2005). As três modalidades de CAPS se diferenciam de acordo com o número de habitantes no município e número de profissionais no serviço, mas todos os CAPS atendem pessoas com transtornos mentais severos e persistentes. São realizados atendimentos individuais e grupais, oficinas, atendimento à família e atividades comunitárias, além disso, no CAPS III há acolhimento noturno contínuo: com no máximo cinco leitos para internaçōes curtas, seu funcionamento é 24 horas.

Os principais objetivos de intervenção relatados pelos participantes desta pesquisa em CAPS I são: promover a reinserção social e profissional, favorecer a autonomia, estimular a capacidade produtiva e promover a inclusão social através de atendimentos individuais e em grupo, oficinas terapêuticas e profissionalizantes, atividades externas e grupos com familiares.

Segundo os participantes desta pesquisa, os principais objetivos de intervenção em CAPS II são: promover a reinserção social e profissional, ajudar na organização do cotidiano, resgatar valores e capacidades, elevar autoestima e prevenir novas crises, utilizando as seguintes estratégias: atendimentos individuais e em grupo, oficinas terapêuticas, orientação familiar, atividades externas, orientação em AVD e visitas domiciliares.

Os principais objetivos de intervenção em CAPS III mencionados pelos participantes são: promover a reinserção social, ajudar na organização do cotidiano e resgatar autoestima através das seguintes estratégias: atendimento individual, orientação familiar, atividades expressivas e externas.

Não houve registro de práticas dos terapeutas ocupacionais que participaram do estudo em Unidades Básicas de Saúde e em Serviços Residenciais Terapêuticos.

A partir de 2005, os indicadores de saúde mental integraram-se à sistematização dos serviços de atenção básica. Em 2006 foram incluídos parâmetros para açôes de saúde mental na atenção básica publicados na Portaria MS/GM n. 1.097 e intensificou-se o esforço de garantir o acesso da população, em especial nos pequenos municípios brasileiros, à atenção em saúde mental (BRASIL, 2007). No entanto, as práticas baseadas nestes pressupostos são, ainda, incipientes.

$\mathrm{O}$ apoio às equipes da atenção básica deve acontecer a partir dos CAPS. Vários municípios de menor porte não possuem CAPS, possuindo apenas ambulatórios, havendo necessidade de melhoria da articulação das equipes desses serviços com as equipes da atenção básica (BRASIL, 2007).

As experiências das equipes matriciais de saúde mental estão ainda em construção. A implantação, expansão e qualificação do apoio matricial são os principais desafios para a política de saúde mental e a garantia de acessibilidade à atenção. Um dos maiores desafios do Sistema Único de Saúde é uma de suas principais prioridades: dar conta da integralidade da atenção (BRASIL, 2007). Nele há extrema necessidade de inserção de terapeutas ocupacionais.

Apesar de os dados coletados não identificarem atuação terapêutico-ocupacional nos serviços residenciais terapêuticos, eles respondem às diversas necessidades apresentadas no processo de saída do hospital: local para morar, suporte social, composição de rede social, responsabilização diferenciada de serviços e equipes de saúde mental, possibilitando assim o fechamento dos hospitais psiquiátricos e a condução de processos de reabilitação psicossocial baseados na comunidade e com o resgate da cidadania (MÂNGIA; ROSA, 2002).

Para Saraceno (1996), a preocupação com o habitar deve ser um compromisso da reabilitação psicossocial, não se pode apenas oferecer aos usuários um lugar para estar, mas promover a qualificação 
do habitar, a apropriação do local onde se vive e estimular o protagonismo vinculado ao aumento do poder contratual dessa população.

Os hospitais psiquiátricos no Brasil eram (e continuam sendo) responsáveis tanto pela residência como pelo atendimento terapêutico a pacientes que apresentam transtornos mentais. A redução progressiva de leitos e a reinserção social dos pacientes psiquiátricos devem ser acompanhadas pela reintegração dos internos aos lares de seus familiares ou pela criação de residências terapêuticas (Programa De Volta para Casa, Serviços Residenciais Terapêuticos - SRT) e também, pela expansão dos Centros de Atenção Psicossocial (CAPS), pela inclusão de açôes de saúde mental na atenção básica, Estratégia Saúde da Família (ESF) e outros serviços de saúde, e pelo credenciamento de leitos psiquiátricos em hospitais gerais nas situaçóes em que a internação se faça necessária (KILSZTAJN et al., 2008). Porém, observarmos que o investimento de recursos em serviços extra-hospitalares assim como o planejamento e a execução da Reforma Psiquiátrica têm sido muito tímidos.

Além disso, a desinstitucionalização que tem como objetivo direto garantir a reinserção social, a cidadania e o direito de a pessoa com transtornos mentais conquistar sua autonomia na comunidade deverá também romper o estigma contra os "loucos" e libertar os "normais" de seu aprisionamento na estrutura funcional das sociedades ditas modernas (KILSZTAJN et al., 2008).

Em relação ao tempo de trabalho em saúde mental, houve o predomínio de cinco $(33,33 \%)$ dos participantes com 5 a 10 anos de trabalho na área de saúde mental.

Foi pedido para que os participantes colocassem em ordem de prioridade os princípios e diretrizes das políticas públicas em saúde mental e eles dividiram esses princípios e diretrizes em dois grupos: primeiramente os princípios do SUS (Universalidade, Equidade e Integralidade), somente depois desses são apontados os princípios que norteiam os pressupostos teóricos relacionados à Reabilitação Psicossocial como: Rede Social, Contratualidade, Território e Habitat. Os participantes listaram, da maior para a menor prioridade: rede social, contratualidade, território e habitat.

Para Pitta (1996), a reabilitação psicossocial representa um conjunto de programas e serviços que se desenvolvem para facilitar a vida de pessoas com problemas severos e persistentes de saúde mental. Para Saraceno (1996), o processo de reabilitação é um exercício de cidadania e de contratualidade nos três grandes cenários: habitat, rede social e trabalho com valor social.

A construção da cidadania, ponto essencial da reabilitação psicossocial, depende das variáveis que operam a favor da contratualidade em casa, no trabalho e na rede social. Essas variáveis estão na organização do pessoal dentro de um serviço, no tempo em que estão exercendo sua prática, em qual é a área de atuação, na hospitalidade que se oferece e na garantia da liberdade para tomar decisóes (SARACENO, 1996).

A reabilitação psicossocial é um grande instrumento da Reforma Psiquiátrica, pois no contexto dela tornam-se cada vez mais presentes as estratégias inclusivas de dispositivos voltados à inserção social e à capacitação de usuários em saúde mental.

Em relação às concepçóes dos terapeutas ocupacionais sobre o raciocínio da linha do cuidado em saúde mental, através da análise de conteúdo agrupamos as respostas em 6 categorias de análise, a saber: Desconhecimento do termo - 5 participantes; Sem resposta - 6; Prática baseada na elaboração de projeto terapêutico - 1; Prática baseada em subsídios teóricos do Modelo de Reabilitaçáo Psicossocial - 2; Prática baseada na gestão do trabalho em equipe norteado por princípios de acolhimento e articulação de redes sociais e serviços - 1 participante.

Dois participantes declararam ter buscado conhecimentos a respeito do termo antes de responder ao questionário, algo que poderia ser considerado um viés mas que na realidade foi uma das contribuiçóes desta pesquisa: o incentivo à busca de conhecimentos científicos e atuais.

Ao analisarmos esses dados identificamos que a maioria dos terapeutas ocupacionais não reconhece sua prática como pautada no raciocínio da linha do cuidado, porém, ao relatarem as características de sua atuação, referem lógicas de sistematização da atenção que se assemelham aos pressupostos da linha do cuidado. Este dado pode remeter à inovaçáo de tema ainda não incorporado à atuação profissional mas que, uma vez consolidado, poderá contribuir para a atenção à pessoa em sofrimento psíquico de maneira integral, acolhedora e humanizada em suas diferentes necessidades, fortalecendo a rede de relaçốes e contratualidade social.

A constituição de um campo de atuação em terapia ocupacional se consolida pela capacidade de escutar, acolher e delimitar com clareza as demandas por seu cuidado e capacidade de articulação e efetivação de suas açôes, de forma que seu papel seja compreendido e incluído, passando sua contribuição 
a compor a lista de serviços requisitados pelo campo mais amplo, constituindo assim o campo-espelho (GALHEIGO, 2008).

Para Galheigo (2008), o desafio da terapia ocupacional no campo da produçáo do cuidado somente se consolida para além dos cuidados clínicos dos processos saúde-doença, sendo possível somente se constituir a partir da perspectiva da integralidade e da humanização do cuidado, do exercício de um olhar menos fragmentador e mais crítico à visão hospitalocêntrica ainda presente. Deve-se buscar desenvolver escuta e acolhimento às necessidades $\mathrm{e}$ problemáticas dos sujeitos sob cuidado, deslocando o hospital do eixo da assistência à saúde e entendendo-o como estação do cuidado. Ao oferecer atenção a partir de linhas do cuidado, as práticas e saberes produzidos pela terapia ocupacional poderão percorrer itinerários nas diferentes linhas, passando pela atenção primária, secundária e terciária e parando em várias "estações do cuidado".

Para esta autora, a terapia ocupacional deve refletir sobre que "caixas de ferramentas tecnológicas" possui (ou necessita adquirir), citando Merhy (2005), a fim de desenvolver açóes de promoção, proteção e recuperação da saúde, de prevenção de agravos e de reabilitação que venham atender às necessidades de saúde demandadas. Açóes que garantam ao sujeito e sua rede social serem compreendidos e cuidados a partir de uma escuta mais ampla de suas necessidades, evitando-se assim tanto abordagens teórico-metodológicas tomadas a priori (a partir da opção de especialidade do terapeuta ocupacional), como racionalidades mais idealizadas do sistema de saúde e menos próximas das necessidades dos seus usuários.

Para o terapeuta ocupacional cujo foco de açáo são as atividades e cotidiano, o cuidado à saúde que disponibiliza constitui-se em poder entender e intervir nas manifestaçôes e descontinuidades da cotidianidade ocasionadas por situaçôes diversas de adoecimento, que transitam pelo domicílio, hospital, e/ou por outros equipamentos sociais e de saúde. Assim, cabe a ele/ela refletir cada vez mais sobre qual é o diferencial da terapia ocupacional na abordagem dos processos saúde-doença e das necessidades da populaçáo que requer cuidados clínicos, construindo açôes fundadas na integralidade e na humanização do cuidado, nos diferentes níveis de atenção à saúde, para os diferentes equipamentos sociais e de saúde, em cada estação do cuidado (GALHEIGO, 2008).

\section{Conclusão}

Concluí-se que o raciocínio da linha do cuidado em saúde mental busca garantir a cidadania e a qualidade de vida das pessoas em sofrimento psíquico, a partir da sistematização da atenção, seguindo o fluxo de necessidades da pessoa, em um cuidado integral, contínuo e humanizado, constituindo redes de relaçóes sociais, o que não significa somente existência de serviços mas sim a promoção de trocas sociais.

As práticas terapêutico-ocupacionais baseadas na linha do cuidado poderão contribuir para o desenvolvimento da autonomia e da cidadania e para a reinserção no mercado de trabalho e na sociedade das pessoas em sofrimento psíquico, promovendo a qualidade de vida, uma vez que a ênfase da profissão está centrada no resgate dos papéis e do desempenho ocupacional da pessoa mediante no contexto em que vive.

\section{Referências}

BARDIN, L. Análise de Conteúdo. Lisboa: Ediçóes 70, 2004.

BRASIL. Ministério da Saúde. Secretaria da Atenção à Saúde. Reforma psiquiátrica e política de saúde mental no Brasil. In: CONFERÊNCIA REGIONAL DE REFORMA DOS SERVIÇOS DE SAÚDE MENTAL: 15 ANOS DEPOIS DE CARACAS, 2005, Brasília. Anais... Brasília: OPAS, 2005. p. 1-60.

BRASIL. Ministério da Saúde. Secretaria de Atenção à Saúde. Relatório de Gestão 2003-2006: saúde mental no SUS: acesso ao tratamento e mudança do modelo de atenção. Brasília: Ministério da Saúde, 2007. p. 1-78.

CECCIM, R. B.; FERLA, A. A. Linha de cuidado: a imagem da mandala na gestãoem rede de práticas cuidadoras para uma outra educação dos profissionaisde saúde. In: PINHEIRO, R.; MATTOS, R. A. (Orgs.). Gestão em redes: práticas, avaliação, formação e participação na saúde. Rio de Janeiro: CEPESC, 2006. p.165-84.

CAMPOS, G. W. S. Clínica e Saúde Coletiva compartilhadas: teoria Paidéia e reformulação ampliada do trabalho em saúde. In: MINAYO, C. et al. (Orgs.). Tratado de Saúde Coletiva. São Paulo: Hucitec, 2006. p. 53-92.

CAMPOS, G. W. S. Saúde Paidéia. 2. ed. São Paulo: Hucitec, 2003.

CECÍlIO, L. C. Modelos tecno-assistenciais em saúde: da pirâmide ao círculo, uma possibilidade a ser explorada. Caderno de Saúde Pública, Rio de Janeiro, v. 13, n. 3, p. 469-478, 1997. http://dx.doi.org/10.1590/ S0102-311X1997000300022

CECÍLIO, L. C. O.; MERHY, E. E. A integralidade do cuidado como eixo da gestão hospitalar. In: Pinheiro, R.; Mattos, R. A. Construção da Integralidade: cotidiano, saberes e práticas em saúde. Rio de Janeiro: UERJ, IMS, ABRASCO, 2003. p. 197-210.

CUNHA, G. T. A construção da clinica ampliada na atenção básica. São Paulo: Hucitec; 2005.

FLICK, U. Introdução à pesquisa qualitativa. 3. ed. Porto Alegre: Artmed, 2009. 
GALHEIGO, S. M. Terapia ocupacional, a produção do cuidado em saúde e o lugar do hospital: reflexôes sobre a constituição de um campo de saber e prática. Revista de Terapia Ocupacional da Universidade de São Paulo, v. 19, n. 1, p. 20-28, jan./abr. 2008.

GIL, A. C. Métodos e técnicas de pesquisa social. São Paulo: Editora Atlas, 2006.

KILSZTAJN, S. et al. Leitos hospitalares de reforma psiquiátrica no Brasil. Cadernos de Saúde Pública, Rio de Janeiro, v. 24, n. 10, p. 2354-2362, 2008. http://dx.doi. org/10.1590/S0102-311X2008001000016

LOBIONDO-WOOD, G.; HABER, J. Pesquisa em Enfermagem: Métodos, avaliação crítica e utilização. 4. ed. Rio de Janeiro: Guanabara-Koogan, 2001.

MALTA, D. C. et al. Perspectivas da regulação na saúde suplementar diante dos modelos assistenciais. Ciência e Saúde Coletiva, Rio de Janeiro, v. 9, n. 2, p. 433-44, 2004. http://dx.doi.org/10.1590/S1413-81232004000200019

MÂNGIA, E. F. A trajetória da terapia ocupacional da psiquiatria às novas instituições e estratégias de promoção de saúde mental. Revista de Terapia Ocupacional da Universidade de São Paulo, São Paulo, v. 11, n. 1, p. 28-32, 2000.

MÂNGIA, E. F.; ROSA, C. A. Desinstitucionalização e serviços residenciais terapêuticos. Revista de Terapia
Ocupacional da Universidade de São Paulo, São Paulo, v. 13, n. 2, p. 71-77, 2002.

MERHY, E. E. O desafio que a educação permanente tem em si: a pedagogia da implicação. Interface: Comunicacao, Saude, Educacao, Botucatu, v. 9, n. 16, p. 161-77, set./fev. 2005. http://dx.doi.org/10.1590/ S1414-32832005000100015

MINAYO, M. C. S.; GOMES, S. F. D. R. Pesquisa Social: teoria, método e criatividade. Petrópolis: Vozes, 2002.

PINTO, H. A. Linhas de Cuidado na Bahia: Um conceito em viva produção. Revista Baiana de Saúde Pública, Salvador, v. 33, n. 1, p. 22-34, 2009.

PITTA, A. M. F. O que é reabilitação psicossocial no Brasil, hoje? In: PITTA, A. Reabilitação psicossocial no Brasil. São Paulo: Hucitec, 1996. p. 19-30.

SARACENO, B. Reabilitação Psicossocial: uma estratégia para a passagem do milênio. In: PITTA, A. M. F. Reabilitação psicossocial no Brasil. São Paulo: Hucitec, 1996. p. 13-18.

WACHHOLZ, S. M. S.; MARIOTTI, M. C. A participação do terapeuta ocupacional na reforma psiquiátrica e nos novos serviços de saúde mental. Cadernos de Terapia Ocupacional da UFSCar, São Carlos, v. 17, n. 2, p. 147-159, 2009.

\section{Contribuição dos Autores}

Michelle Helena Pereira de Paiva: Contribuiu com concepção e delineamento do estudo, busca a literatura, levantamento dos dados, coleta de dados, análise e interpretação dos dados e redação do artigo. Heloísa Cristina Figueiredo Frizzo: Contribuiu com busca a literatura, levantamento dos dados, análise e interpretação dos dados, revisão crítica do artigo com relação ao seu conteúdo intelectual e aprovação final do artigo para envio para revista.

\section{Notas}

${ }^{1}$ Trabalho de Conclusão de Curso (Julho 2010) apresentado ao Curso de Terapia Ocupacional da Universidade Federal do Triângulo Mineiro - UFTM, aprovado pelo Comitê de Ética em Pesquisa em Seres Humanos. 
